\title{
¿Es necesario transitar a un nuevo paradigma civilizatorio y de derechos humanos?*
}

\author{
Is it necessary to move into a new civilizational \\ and human rights paradigm? \\ César Eder Alanís de la Vega \\ Universidad Autónoma de San Luis Potosí \\ cesar_alanis@alumnos.uaslp.edu.mx
}

Sumario: Introducción. 1. La crisis humanitaria y ecológica del paradigma civilizatorio moderno: capitalismo y vida son incompatibles.

2. El sistema imperial de los derechos humanos (contraderechos) en el paradigma civilizatorio moderno. 3. La respuesta del sistema capitalista. 4. ¿La necesidad de transitar a un nuevo paradigma? Referencias bibliográficas.

Resumen: En el presente trabajo se analiza el funcionamiento y la lógica que subyace al paradigma civilizatorio moderno, mediante el análisis sistémico propuesto por Wallerstein y cómo ello configura el Derecho. Afirmamos que el capitalismo, y la producción y reproducción de la vida de los pueblos y del Sistema-Tierra, es incompatible. Ya que el primero requiere de la destrucción del segundo para poder existir. En ese sentido, nos preguntamos si a partir de la lógica del capital, la cual configura también a los derechos humanos, es posible imaginar una verdadera solución radical al problema de la crisis ecológica y humanitaria. Esto con el objetivo de que, como personas investigadoras y defensoras de los derechos humanos, empecemos a replantearnos las teorías hegemónicas del Derecho, y formular praxis creativas frente a la inminente amenaza que representa el sistema capitalista.

Palabras clave: Sistema-mundo capitalista, crisis ecológica, crisis humanitaria, derechos humanos, paradigma civilizatorio.

Abstract: This paper explores the dynamics and the logic underlying the modern civilizational paradigm through the systemic analysis proposed

* Cómo citar: Alanís de la Vega, César Eder. 2019. “ ¿Es necesario transitar a un nuevo paradigma civilizatorio y de derechos humanos?". Deusto Journal of Human Rights, 4: 227-253. http://dx.doi.org/18543/djhr-4-2019pp227-253 
by Wallerstein and how it shapes the Law. We argue that capitalism and the production and reproduction of human life and the Earth-System are incompatible, since the former requires the destruction of the latter. In this context, we wonder if, basing on the logic of capital, which also shapes human rights, it is possible to imagine a truly radical solution to the problem of the ecological and humanitarian crisis. The main goal here would be that we, as researchers and defenders of human rights, begin to rethink the hegemonic theories of law and to formulate creative praxis against the challenges posed by the capitalist system.

Keyword: Capitalist world-system, ecological crisis, humanitarian crisis, human rights, civilizational paradigm. 


\section{Introducción}

Cuando los índices de pobreza monetaria marcan que existen 3.400 millones de personas pobres en el mundo, la gran mayoría concentrada en el Sur Global. Cuando el modelo civilizatorio moderno es quizá el más pobre de la historia de la humanidad, porque existen altos índices de indigencia de satisfactores materiales que impiden el florecimiento de las capacidades y satisfacción de las necesidades de los pueblos. Cuando la integridad de la biosfera está altamente comprometida y el ritmo de pérdida de biodiversidad es tal que ya se habla de "una sexta extinción" de origen antropocéntrico. Cuando las tierras donde se cosecha el trigo para los pobres se están volviendo cada vez más infértiles, el agua que sacia la sed a los sedientos se está agotando y contaminando, y los bosques y selvas que visten de verdor al planeta y sirven de templos naturales para el florecimiento de la diversidad de la vida, se están desnudando ferozmente. Cuando se están ocasionando grandes holocaustos naturales y humanos, y reina la indiferencia en las mayorías. Cuando el Dios de los pobres es más bien el Dios de las riquezas (Mammón), el cual para vivir exige el sacrificio de sus hijos y de todo lo creado, haciendo correr ríos de sangre y multiplicando los desiertos estériles, significa que algo va mal, muy mal.

Esto nos obliga a preguntarnos sobre las causas que lo originan, pero más que las causas es importante entender la totalidad sistémica que está detrás. La respuesta es a la vez sencilla y compleja de explicar y varía mucho desde dónde nos situemos para contestarla. Por supuesto, esto se debe al modelo de producción capitalista y su lógica de acumulación depredadora y destructiva. El sistema en su totalidad es el problema, porque condiciona las praxis y estructura los fundamentos de la vida colectiva en función de esa lógica. Pero, como demostraremos, este sistema también despliega una totalidad jurídica global, un sistema-mundo jurídico que responde al paradigma civilizatorio capitalista, y que tiene por presupuestos ideológicos a la modernidad colonialidad — dotándole de sentido-.

\section{La crisis humanitaria y ecológica del paradigma civilizatorio moderno: capitalismo y vida son incompatibles}

El modelo de producción capitalista, y su lógica de acumulación ilimitada, no consigue producir riqueza y desarrollo sin producir simultáneamente degradación ambiental y socavar la corporalidad humana que sufre la desigualdad social. En cuanto a la crisis ecológica, 
el mito del progreso y el crecimiento ininterrumpido e ilimitado, el gran metarrelato moderno, ha montado una máquina industrialistaproductivista y publicitaria fantástica. Se han agilizado todas las fuerzas productivas para extraer todo en cuanto se pueda de la naturaleza, y crear un culto a la mercancía, para consumirla, mediante ágiles estrategas publicitarias (produciendo falsos satisfactores). En palabras de Boff, "se ha organizado un asalto sistemático a sus riquezas en el suelo, en el subsuelo, en el aire, en los mares, en la atmósfera exterior. Se ha llevado la guerra a todos los frentes" (Boff 2011, 88). La producción de víctimas es inaudita. Cada vez son más los grandes templos de la biodiversidad del planeta que son transgredidos por la lógica de acumulación, despojando de manera violenta a sus guardianes históricos de los espacios territoriales, y ocasionando grandes holocaustos naturales y humanos (p.ej. el Amazonas). La muerte, y no la vida, prevalece. Al mismo tiempo, el capitalismo produce inevitablemente desigualdad en la distribución de la riqueza. En la actualidad, según datos de Oxfam Internacional, el 99\% de la población mundial posee menos riqueza que el $1 \%$ más pudiente de la población del planeta. Y aunque datos de otros estudios puedan ser más optimistas, lo que es un hecho es que la acumulación de capital privado conduce a la concentración cada vez mayor de la riqueza y el poder en unas cuantas manos ${ }^{2}$. La estructuración del capitalismo está en función a la lógica de la acumulación. La pregunta que surge ante estos hechos es: ¿qué los origina? ¿Por qué afirmamos que capitalismo y vida son incompatibles? Para ello es importante entender la totalidad sistémica que está detrás.

Marx señalaba como punto de origen del capital (la esencia del capitalismo) una acumulación originaria previa a la acumulación del capital, una acumulación que no es resultado del modo de producción capitalista, sino su punto de partida. Esta acumulación es posible gracias a la disolución de la propiedad colectiva de la tierra y de otros bienes comunes ahí contenidos. Se trata de un despojo doble, de los bienes comunes y del trabajo. La persona queda desnuda frente al capital, solo con su corporalidad que prostituye al capitalista para

2 Este número de pobreza es medido con los estándares de pobreza monetaria. Si se mide con los criterios de pobreza humana (p.ej. los señalados directa o indirectamente por K. Marx, G. Markus, E. Fromm, J. Boltvinik, etc.,) resulta que la sociedad moderna es quizá de las más pobres de la historia de la humanidad. ¡Tan pobre que no ve su pobreza! Cabe señalar que por riqueza, desde la teoría materialista de las necesidades/ capacidades, se entiende el florecimiento de las capacidades y satisfacción de las necesidades de los pueblos. 
poder reproducir su vida, mientras que la naturaleza queda dispuesta a ser torturada y convertirse en mercancía. Ambos están listos para ser sacrificados y mantener con su sangre y destrucción al Dios Mammón. Esta "etapa originaria" deja de ser relevante para algunos autores debido a su adjetivo "originario", es decir, es vista como una etapa ya superada. Sin embargo, esa acumulación basada en el fraude, la depredación y la violencia, y legitimada por la fuerza del derecho (un derecho expropiatorio) es, para Harvey, una práctica persistente del capitalismo: "Dado que denominar 'primitivo' u 'originario' a un proceso en curso parece desacertado, en adelante voy a sustituir estos términos por el concepto de 'acumulación por desposesión'" (Harvey 2005, 113). Así, el capitalismo instaló el despojo, un patrón de poder expropiatorio como parte estructural del funcionamiento del actual sistema de producción. Este despojo se ha ido agudizando y configurando a lo largo de la evolución del sistema-mundo capitalista, ajustándose y renovándose de acuerdo con las condiciones y exigencias necesarias para seguir acumulando más capital, y superar al menos de forma provisional algunas de sus contradicciones sistémicas.

Harvey (2005) retoma a Marx en la descripción que hace sobre la acumulación originaria con el objetivo de revelar el rango de los procesos por desposesión. Estos incluyen:

la mercantilización y privatización de la tierra y la expulsión forzosa de las poblaciones campesinas; la conversión de diversas formas de derechos de propiedad —común, colectiva, estatal, etc. - en derechos de propiedad exclusivos; la supresión del derecho a los bienes comunes; la transformación de la fuerza de trabajo en mercancía y la supresión de formas de producción y consumo alternativas; los procesos coloniales, neocoloniales e imperiales de apropiación de activos incluyendo los recursos naturales; la monetización de los intercambios y la recaudación de impuestos, particularmente de la tierra; el tráfico de esclavos; y la usura, la deuda pública y, finalmente, el sistema de crédito. (Harvey 2005, 113)

La desposesión o despojo en Harvey, se ha ido agudizando conforme a las exigencias de la acumulación para superar, al menos momentáneamente, las contradicciones del sistema. Harvey señala que han aparecido nuevos mecanismos de acumulación por desposesión, por ejemplo, las patentes y licencias de los materiales genéticos como la plasma de semillas, la biopiratería, el pillaje del stock mundial de recursos genéticos en beneficios de unas cuantas empresas; y la reciente depredación de los bienes ambientales (agua, tierra, aire) y proliferación de la degradación ambiental han resultado en la 
total transformación de la naturaleza en mercancía. La fuerza de la acumulación conlleva a la mercantilización de todas las cosas (si no de dónde se obtendrían nuevas ganancias). Ya Karl Polanyi (2006) advertía que el capital es una formidable máquina de cosificación, es decir, que la economía capitalista de mercado se ha automatizado y funciona según sus propias leyes, leyes impersonales del beneficio y la acumulación (desencajadas de la sociedad). Esto supone "simplemente la transformación de la sustancia natural y humana de la sociedad en mercancía" (Polanyi, 2006, 49). Y, toda mercancía cuando deja de producir valor es descartada, desechada. Cuánta razón encarnan las palabras de Marx cuando señala que: "el capital es trabajo muerto que solo se reanima, a la manera del vampiro, al chupar trabajo vivo [y la naturaleza] y que vive más cuanto más trabajo vivo chupa [y cuanto más destruye a la naturaleza]" (Marx 2006, 191).

Es un sistema ecocida. Marx a través de su estudio científico del capital pudo "intuir" que la destrucción ecológica es necesaria para el funcionamiento del capitalismo, solo que no fue capaz de dimensionar sus alcances y la complejidad de sus contradicciones ${ }^{3}$. Para Marx, el modelo de producción capitalista:

no solo destruye la salud física de los obreros urbanos y la vida espiritual de los trabajadores rurales, sino que además altera los intercambios materiales entre el hombre y la tierra, y la condición eterna de la fertilidad duradera del suelo [...] La producción capitalista, por tanto, no desarrolla la técnica y la combinación del proceso social sino socavando al mismo tiempo las dos fuentes de donde emana toda riqueza: la tierra y el trabajador. (Marx 2006, 390)

Así, la fractura metabólica es inherente al modelo de producción capitalista. Esta consiste en la ruptura en el sistema de intercambios materiales entre la Tierra y la satisfacción de las necesidades materiales de los seres humanos, en contradicción con las "leyes de la vida" (las fronteras planetarias) (Houtart et al. 2017, 154). La fractura metabólica está íntimamente asociada a la acumulación por desposesión, pues mientras esta acumulación se ha mantenido y ahondado, asociado

3 Michael Löwy (2012) señala que los asuntos ecológicos no tienen un lugar central en el dispositivo teórico marxista, lo cual no implica que Marx y Engels no hayan señalado las consecuencias ecológicas inherentes al desarrollo de las fuerzas capitalistas de su época. En ese sentido, el ecosocialismo es de gran ayuda para realizar una lectura de la realidad desde la mirada del otro gran oprimido y doblemente descartado por el capital: el Sistema-Tierra. 
a ello se ha incrementado con creces los llamados flujos biofísicos o energético-materiales. Somos una sociedad altamente energívora. En concordancia con lo anterior, nuestros flujos de residuos han incrementado, si consumimos más desechamos más, por ende, la degradación ambiental va en ascenso. Esto explica por qué en los últimos años se fue consolidando una nueva modalidad de rentabilidad en los territorios como sumideros de residuos tóxicos, un nuevo mecanismo de acumulación por desposesión. Donde el capital ve una oportunidad de ganancia tratará a como dé lugar de penetrar en las relaciones sociales y espacios territoriales, sometiéndolos y configurándolos a los imperativos de valorización.

En este punto, son útiles las críticas aportadas por el ecosocialista James O'Connor, quien encuentra una segunda contradicción a la primera desarrollada por Marx4. Para O'Connor (2001, 201-202), "la incesante búsqueda de acumulación capitalista, perjudica o destruye las propias condiciones del capital debido a los límites naturales que se imponen al propio proceso de acumulación, que apropia y utiliza de manera autodestructiva las condiciones de producción, generando una crisis de costos". Para acumular más, el capital degrada las condiciones materiales y sociales de su propia producción. Este es el caso, por ejemplo, del descuido de las condiciones de trabajo con el objetivo de abaratar sus costos, lo que termina por producir un incremento de los costos sanitarios, de la degradación de los suelos y destrucción de los espacios socioterritoriales que encontramos en la producción de monocultivos, tan necesarios para que el capital pueda obtener ganancia en los agrocombustibles y superar la futura escasez de energía, o la desatención de las infraestructuras urbanas en proceso de deterioro, solo por mencionar algunos ejemplos.

Claro está que el despojo y su patrón de poder expropiatorio, como parte estructural del funcionamiento del actual sistema de producción, y su destrucción de los espacios socio-territoriales, se ordenan en función de la estructuración del sistema interestatal del sistema-mundo

4 Existen dos contradicciones del sistema capitalista. La primera contradicción es interna al sistema capital y se concentra en la dominación política y social del capital sobre el trabajo, lo que explica la causa de la desigualdad sistémica de la población en función de la división social del trabajo a nivel mundial, y la extracción y transferencia de su plusvalor (trabajo no pagado). Esta es la contradicción clásica propuesta por Marx. La segunda contradicción es externa al sistema y se da entre las fuerzas productivas y las fuerzas de trabajo con las condiciones de producción. O'Connor $(2000,22-23)$ define las condiciones de producción como "cosas que no son producidas como mercancías de acuerdo con las leyes de mercado (ley de valor), pero son tratadas como si fueran mercancías. En otras palabras, se trata de bienes ficticios con precios fijos". 
capitalista propuesto por Wallerstein (2017): centro, semiperiferia y periferia. Por tanto, es patente el despojo estructurado (por ejemplo, de los recursos naturales) del Norte sobre el Sur, con graves implicaciones que de forma deliberada afectan a las comunidades pobres y excluidas. No es extraño entonces, que hoy se destine el $80 \%$ de los recursos naturales, explotados principalmente en los países del Sur, para el consumo individualizado del $20 \%$ de la población mundial concentrada en el Norte (Houtart et al., 2017). Así, el Sur, además del fenómeno de la deuda externa, adquiere una deuda ecológica, pues es el Sur quien paga las consecuencias de las externalidades (daños a la naturaleza e injusticias sociales) provocadas por el Norte.

La hegemonía del capitalismo no puede explicarse solo por su patrón de poder expropiatorio que despoja para acumular: necesita colonizar las mentes, la aceptación de la reproducción de las relaciones de dominación en la vida cotidiana. Quijano $(2014,777-832)$ y su categoría de colonialidad, señala como característica del patrón de poder capitalista a la clasificación de la población mundial sobre la idea de raza —y Lugones (2008) agregará "género" ${ }^{5}$, y desde el marxismo se agrega "clase" - . Asocia la idea de modernidad a una racionalidad específica y eurocéntrica. Todo esto en función del despliegue del capitalismo en América. Modernidad, capitalismo y colonialidad fueron configurando las bases materiales y sociales y su producción de ideas desde 1492, que se impondrá como modelo civilizatorio al resto del mundo, y que ha seguido un proceso de contradicciones internas (dialéctico).

El patriarcado está presente en el Antiguo y Nuevo Testamento. Los valores masculinos ocupan los principales espacios sociales. Dios mismo es presentado como un Padre y Señor, una masculinización de la divinidad que ordena y ejecuta. "El padre Celestial promete la salvación si se desprecia el cuerpo y se aspira a una existencia liberada de toda relación con la naturaleza" (Puleo 2011,48). Las mujeres son reducidas

5 Para Lugones (2008) no solo la raza es un elemento clasificador de las relaciones sociales de poder, también el género. Lugones crítica a Quijano en su propuesta de colonialidad del poder al concebir el género sin relación con la raza. Por esto, cuando se habla de "negro" se asocia al hombre "negro", invisibilizando a la mujer "negra" y la doble opresión que ocupa en función de las estructuras de poder. De ahí que se deba de problematizar desde el género nuestros enfoques teóricos y prácticos, de lo contrario caeríamos en reproducir la lógica patriarcal moderna y seguir con las praxis de dominación, apropiación y explotación, "encubiertas de liberación", sobre los cuerpos femeninos que se vienen gestando en América desde 1492, y que muchas de las veces son invisibilizadas por no ser conscientes de ello. Normalizamos la violencia y legitimamos sus estructuras. 
al espacio de lo privado e identificadas con la naturaleza, lo "salvaje", lo "bruto", y tentadoras de la corporalidad masculina. Para Segato (2018), el despliegue de la conformación del sistema-mundo capitalistamoderno-colonial produce una mutación histórica de la estructura de género. El sujeto "masculino" (blanco, heterosexual, cristiano, burgués, europeo) se vuelve modelo de lo humano y sujeto de enunciación paradigmático de la esfera pública, al mismo tiempo que el espacio de las mujeres y todo lo relacionado con la escena doméstica "se vacía de su politicidad y vínculos corporados, de alianza y cooperación, de que gozaba en la vida comunal, para transformarse en margen y resto de la política" (Segato 2018, 4). El espacio doméstico adquiere así los predicados de íntimo y privado. El trabajo para el mantenimiento de la vida (reproductivo y de cuidado) es atribuido exclusivamente a las mujeres, sin el cual sería imposible la reproducción social. "El trabajo de las mujeres en el hogar del patriarcado capitalista consiste en una mediación con la naturaleza en beneficio de los hombres: satisfacción sexual, nacimiento y alimentación de los bebés, transportar a los más jóvenes, proteger sus cuerpos y socializarlos, cultivar y preparar los alimentos, mantener la vivienda..." (Puleo 2011, 65).

En relación con la raza, que para Quijano (2014) no tiene historia conocida antes de América ${ }^{6}$, se visibiliza mejor la opresión que ocupan las mujeres y hombres en función a las estructuras de poder. La mujer europea ocupó un rango superior que la mujer "nativa", "negra", "indígena", dentro de la escala patriarcal del patrón de clasificación. No es la misma "experiencia" y "horizonte de expectativas" de una mujer indígena perteneciente a la huasteca potosina, que es atravesada por la raza y el género de la colonialidad y el patriarcado, y además es relegada en la marginalidad económica por no ser "productiva" a los ojos del capitalismo (la clase), frente a una mujer europea de suburbios con acceso a una educación universitaria, que reclama igualdad en las prestaciones sociales ante la agudización de la explotación de las fuerzas de trabajo por el neoliberalismo. Es importante mencionar que el patriarcado no solo oprime y expolia el cuerpo de las mujeres, también oprime y moldea al hombre, y le exige constantes pruebas

6 Abdennur Prado (2018) señala la existencia de una dimensión teológica del racismo, premoderna, en razón al "linaje" o "pureza de sangre", no con un significado biológico, justamente poco antes de iniciar la empresa de la Conquista de América, en el contexto de la expulsión de los moros de Nueva Granada. Se puede considerar esta experiencia como la antesala de una política de segregación y estratificación social para justificar la expansión territorial en América. Sin embargo, en la Conquista de América existe un gran salto cualitativo de la raza como dispositivo de control, generando devastadoras consecuencias. 
de la pertenencia a la clase de los "hombres", propias de su género (Segato 2018, 2).

En cuanto a la clase, vislumbrarla solo desde su contradicción material entre dos clases antagónicas, burguesía y proletariado, cae en una comprensión reduccionista y economicista del entramado complejo y estructural del poder en el sistema-mundo capitalistamoderno-colonial, invisibilizando a tres cuartas partes de la población mundial, que no es ni burguesa ni proletaria en el sentido estricto y eurocéntrico de la construcción social de estas categorías. Por ejemplo, la organización del modelo de producción del "indígena" para el marxismo ortodoxo no se puede considerar comunista, pues no se han desarrollado primero las relaciones de producción capitalistas que configuran las condiciones necesarias para el tránsito hacia el socialismo. Los "indígenas" y "negros" necesitan subjetivarse en proletariados para poder aspirar a una transformación social. ¡Nada más contrario a Marx! Esto infiere una consecuencia interesante: sin la existencia del proletariado no se puede hablar de capitalismo, por lo tanto, no se puede hablar en sentido estricto de capitalismo en América durante la conquista y su despliegue, borrando de un plumazo el papel que jugó América y su configuración con la modernidad-colonialidad. Por esto, no es extraño que los marxismos ortodoxos identifiquen el paradigma civilizatorio como un paradigma económico capitalista, limitando su praxis de liberación exclusivamente a resolver los problemas de "clase", como si reapropiándose de los medios de producción y desarrollando ilimitadamente a las fuerzas productivas en automático desaparecerán las otras opresiones (raza-género) y el Sistema-Tierra dejará de ser expoliado7. No obstante, no podemos negar la existencia de los problemas de clase que la estructura del despojo capitalista produce. Relacionar la clase al género y la raza permite comprender, por ejemplo, la existencia de una burguesía Aymara mayoritariamente masculina, que invisibiliza su pertenencia a una clase a través de un esencialismo indígena y reivindica un proyecto etnonacionalista, no encontrando en sus discursos la diferencia entre indígenas pobres y ricos, ya que solo se parte del hecho de ser "indígena" (Stefanoni, 2010a y 2010b).

7 Esto se debe principalmente al reduccionismo economicista propagado por algunas interpretaciones dogmáticas del marxismo. Este consiste en que el análisis de la estructura o base económica de la sociedad es un elemento que en última instancia determina todas las relaciones sociales y se expresa también en expresiones en la superestructura ideológica, política y jurídica de la sociedad. Sin duda, esta visión reduccionista y simplificadora hiperbolizará la significación del factor económico en detrimento de la necesaria visión holística e integradora de la modernidad. 
La raza/género/clase fueron establecidos como instrumentos de clasificación social básica de la población mundial y configuración de las estructuras del despojo, que también incluye el cuerpo de las mujeres; por eso tanto el despojo como sus consecuencias en las relaciones socioterritoriales y ambientales son de gran calado en las comunidades pobres y excluidas del Sur, afectando doblemente a las mujeres, con el fin de mantener los "privilegios" del Norte. Por otra parte, la raza/género/clase permite tomar conciencia del "lugar desde donde se enuncia la praxis" y "quien realiza la praxis", y esto es importante porque, si no tomamos conciencia de ello, correremos el riesgo de seguir reproduciendo y legitimando, en nuestros discursos y acciones, las estructuras de dominación y explotación del capitalismo moderno-colonial. A esto hay que agregarle al otro gran oprimido por el ser humano: el Sistema-Tierra, pues ¿de qué sirve la praxis de liberación de las subjetividades atravesadas por la raza/género/clase si no retoman en su clamor los gritos de la Tierra? No se trata solo de la liberación de la explotación del humano por el humano, sino de la liberación que nos permita a todos vivir en armonía con la naturaleza y sentirnos religados a ella, y ello nos incluye, ¿o acaso no somos parte de la naturaleza y compartimos un mismo origen?

En conclusión, capitalismo y vida son incompatibles, ya que requiere del sacrificio de la vida, que "devora" a los humanos y socava a la naturaleza para seguir reanimándose. Trata de lavar la sangre de este sacrificio justificándose con presupuestos ideológicos que terminan por someter a los pueblos en "servidumbre voluntaria". Por esto afirmamos que el paradigma civilizatorio moderno, el fetiche construido por la sórdida avaricia del cristiano burgués y reproducido por el balido incesante de sus corderos "ideologizados", nos está conduciendo a la muerte de todo lo existente, desatando una crisis humanitaria y ecológica sin precedentes en la historia de la humanidad. Todo esto también configura un sistema estructural y dinámico, que se ha denominado "maliciosamente" de derechos humanos (contraderechos).

\section{El sistema imperial de los derechos humanos (contraderechos) en el paradigma civilizatorio moderno}

Hace 500 años, los españoles dan comienzo a la guerra expropiatoria imperial de las tierras, medios de producción y fuerza de trabajo de los pueblos originarios. Con ello se da comienzo al despliegue de las relaciones imperialistas y coloniales del naciente 
sistema-mundo, configurando la estructura del despojo, un patrón de poder expropiatorio violento como parte estructural del funcionamiento del actual sistema de producción. Para Antonio Salamanca (2011a, 2011b y 2016), no solo nos expropiaron las tierras y los bienes comunes ahí contenidos, también el derecho. En consecuencia, se puede hablar de una expropiación originaria del derecho de los pueblos y apropiación de su pluspoder, para imponer un sistema imperial de contraderechos (un sistema-mundo jurídico), que expropia la consciencia del estado del sistema de necesidades/capacidades populares, y los medios de positivización, así como la fuerza jurídica positivadora. En pocas palabras, elimina la participación del pueblo en la creación de sus propias costumbres jurídicas y leyes legítimas y su capacidad coactiva de poner al derecho en acción de la satisfacción de sus necesidades materiales, imponiendo un falso Derecho.

La tradición iusmaterial parte del "hecho del Derecho". Y el hecho del Derecho es "la praxis de los pueblos de producción, circulación y apropiación de satisfactores de su sistema de necesidades/capacidades, con la ayuda de la fuerza física coactiva de la comunidad" [su pluspoder] (Salamanca 2011a, 33). El derecho es una acción, una praxis, no un texto que lo inmoviliza y virtualiza las necesidades materiales de los pueblos, despojándolos de su capacidad de poder satisfacerlas. Para el iusmaterialismo, el Derecho y "sus derechos" se fundan en la materialidad, pues reconoce el estado de necesidad histórico de los pueblos, recuperando la corporalidad viviente transida de necesidades, como lo haría Marx, de la vida de los sujetos en comunidad, y que la modernidad vació en un sujeto abstracto. "Los pueblos están determinados y forzados por su sistema de necesidades/capacidades" (Salamanca 2011a, 156). Toda necesidad se funda en las exigencias que impone la vida, "la especie homo sapiens sapiens, y de la misma materia del cosmos; un sistema de necesidades/capacidades que le es propio a la especie" (Salamanca 2010, 99). El sistema de necesidades/ capacidades es una constante histórica del homo sapiens sapiens ${ }^{8}$. En cambio, los satisfactores para estas necesidades sí están abiertos a creación histórica y sociocultural, ya que varían de acuerdo con las particularidades históricas y con las condiciones materiales que impone el circuito natural de los pueblos. Por ejemplo, no todos

8 Salamanca (2011b) propone un listado de necesidades "materiales" que los pueblos requieren para poder producir, reproducir y desarrollar su vida, las cuales clasifica en tres tipos: Necesidades de comunicación material, necesidades de libertad material y necesidades de verdad material. A cada uno de los tipos corresponde una serie de necesidades. 
comemos lo mismo, sin embargo, todos comemos para poder vivir. No todos hablamos el mismo idioma, pero todos hablamos para poder comunicarnos.

A cada necesidad corresponde un derecho como satisfactor, conformando un sistema estructural dinámico de derechos fundamentales, que Salamanca denomina derechos subjetivos, mejor conocidos como derechos humanos. Así, para el iusmaterialismo, los derechos humanos han existido desde la aparición de la vida comunitaria de la especie homo sapiens sapiens y no, como afirma la doctrina jurídica eurocéntrica y colonial, que el origen de los derechos subjetivos se da gracias a los pensadores europeos como Duns Scoto y Guillermo de Occam. Los derechos humanos no se fundan en una supuesta naturaleza del hombre, ya sea en clave teológica o ilustrada, como lo postula el iusnaturalismo, ni tampoco los otorga el Estado, a través de su positivización en los textos constitucionales, como lo afirma el iuspositivismo, dando lugar al fetiche jurídico.

Sin embargo, se ha impuesto un sistema imperialista de los derechos humanos. Para Salamanca, desde la Conquista y colonización del mundo de la vida, no solo se desplegó un sistema-mundo de matriz capitalista que condicionará la aparición de la modernidad religada a la colonialidad, a la par se desplegó un sistema-mundo jurídico, el cual expropia el derecho a los pueblos - ya sea en sus dos tradiciones common law y romano-germánica - y articula un sistema estructural dinámico de contraderechos global y local, teniendo como presupuestos ideológicos la modernidad-colonialidad que justifican su existencia. En términos de Wallerstein (2017), los Estados más fuertes configuran un sistema-interestatal de reglas (contraderechos) que imponen a los Estados más débiles, de manera violenta, y mediante una guerra expropiatoria continua. Lo vimos con el golpe militar chileno o el nuevo intento de golpe de Estado hacia el pueblo venezolano.

Los países del centro se apropian del plus-poder de los países periféricos para seguir imponiendo el sistema de contraderechos y no permitir que los pueblos adquieran autodeterminación para satisfacer sus propias necesidades/capacidades y ejercer su principal derecho, el de la revolución, pues es justamente el capital quien debe de proveer falsos satisfactores para seguir acumulando más y más. La lógica de la acumulación por despojo y su estructuración no es ajena al derecho, al contrario, gracias a este puede seguir actualizándose en cada momento.

La producción del contraderecho es ideológica. Por el término "ideológica" no se quiere decir que no es real, que no ocurre en el mundo. Salamanca advierte de la virtualización de las necesidades, 
es decir, la desmaterialización del sistema de necesidades que se predican en los discursos idealistas de los derechos humanos, de matriz moderna-colonial. El contraderecho expropia la conciencia y los satisfactores del sistema de necesidades y capacidades de los pueblos y la naturaleza. Sin embargo, el sistema de necesidades/capacidades de los pueblos y la naturaleza sigue, no puede desaparecer, por más que lo traten de encubrir y virtualizar. "Es esta resistencia materialista de alienación ideológica imperial lo que hace difícil tragar [subsumir] a todos los pueblos, y todo el tiempo, que su estado de necesidad, esto es, su ignorancia, hambre y esclavitud, es consecuencia ineludible de su inferioridad cultural, 'indigestión', y subdesarrollo social" (Salamanca 2011a, 48). En pocas palabras, la modernidad-colonialidad se materializa en estructuras jerarquizadoras que coadyuvan al capital a expropiar la conciencia de los pueblos, creándoles falsos satisfactores y alienándolos a justificar a su verdugo; el colonizado busca parecerse a su colonizador.

Podemos distinguir dos tradiciones de los derechos humanos, de acuerdo con el despliegue y configuración sistema-mundo. La primera tradición corresponde a la primera modernidad señalada por Dussel (2004). En esta etapa, Europa era periférica respecto al mundo chino, musulmán e indostánico, y requería de la extracción del oro y la plata para poder comerciar con ellos. Ello explica la gran voracidad destructora sobre los pueblos originarios, la expropiación de su trabajo, imponiendo un sistema de explotación y control de toda forma de trabajo, y el despojo de sus bienes comunes, todo para saciar su sed de oro y plata. Se crea todo un sistema estructural dinámico de contraderechos, conformado por un conjunto de legislaciones (Leyes de Indias) que terminaban por expropiar los satisfactores del sistema de necesidades/capacidades de los pueblos originarios. En respuesta, surge la primera tradición de los derechos humanos - reivindicada por Jesús Antonio de la Torre (2004) y Alejandro Rosillo (2011)_, que nace en América Latina con Bartolomé de Las Casas y el grupo de primeros evangelizadores que pensaban como él, caracterizada por concebir los derechos humanos a partir del pobre. De la Torre (2004) remarca la importancia de esta primera tradición por el uso político que significó en la defensa de los "indios". En contra parte, se distancia de la segunda tradición de corte "ilustrado", ligada a la Revolución Francesa y la Independencia de Estados Unidos, de corte eminentemente individualista, y desarrollada por los burgueses ilustrados que buscaban justificar su ascenso al poder, afirmando su libertad frente al Estado, y la acumulación de tierras y esclavos en los nuevos territorios conquistados (p.ej. Locke). Así, el sistema de 
contraderechos del sistema-mundo jurídico pasó de ser interpretado en clave teológica a clave racionalista y secular (positivista), y funcional a la naciente etapa del capitalismo industrial ${ }^{9}$.

Marx, en La cuestión judía, rechaza la ideología burguesa de los derechos humanos (los contraderechos de la segunda tradición). Para Marx no son otra cosa "que los derechos del miembro de la sociedad burguesa, es decir, del hombre egoísta, del hombre separado del hombre y de la comunidad" (Marx 2016, 28). Son expresión abstracta del idealismo metafísico universalista burgués, que se abstrae de toda determinación espacio temporal y pretende ser eterno, encubriendo su origen geopolítico, y ocultando el sujeto de enunciación; un sujeto sin necesidades materiales, un espíritu que no come ni sufre por el dolor material que le causa su explotación. También es durante esta etapa cuando se consolida el formalismo codificador sea en la deriva normativista (tradición romano-germánico) o jurisprudencial (tradición del common law) suplantando al derecho mismo como praxis jurídica y quitándole fuerza satisfactoria a los derechos humanos. Por lo tanto, la ideología moderna-colonial de los derechos humanos (contraderechos), (i) afirma un universalismo incluyente en el texto y excluyente en la realidad, un universalismo racista/sexista/clasicista, (ii) virtualiza las necesidades/capacidades de los pueblos, y (iii) levantando como fetiche la mediación escrita de la formulación de los derechos humanos, para que se adore por todo el mundo.

Para Salamanca, el sistema imperialista de contraderechos, maliciosamente llamado por los dominadores como derechos humanos, también expropia la ley de los pueblos, su justicia y aplicación. El imperio impone ordenamientos internacionales, nacionales y locales. En el ámbito internacional, la agresión del sistema imperial tiene por objetivo la expropiación del Derecho Internacional de los Pueblos. Escruta permanentemente las Constituciones, leyes y tratados para destrozarlos e imponer el propio dominio ideológico de matriz capitalista-moderna-colonial. En el ámbito nacional, el sistema arrebata a los pueblos toda constitución revolucionaria o lo que haya de revolucionaria en ellas, para terminar de despojar cualquier intento de autodeterminación de los pueblos (de su plus-poder), e imponer el propio dominio ideológico (un colonialismo jurídico interno). Al respecto, no es casualidad que a nivel mundial los principales estudios

9 Es en esta etapa cuando en el sistema-mundo Europa se volvió hegemónica, gracias a la caída del dominio de la región asiática dominada por China y el Indostán, y a la extracción de oro y plata, lo que les permite el desarrollo de la Revolución Industrial. Véase Dussel (2004). 
del derecho respondan a las exigencias del fetiche jurídico del capital, que a grosso modo son:

a) formalismo codificador, normativista o jurisprudencial; b) dogmatismo monodisciplinar; c) colonialismo etnocéntrico; d) enclaustramiento universitario; e) metodología de la investigación monodisciplinar exegético-glosadora de textos; f) pedagogía docente de clase magistral dogmático deductiva. (Salamanca 2016, 153)

La fuerza incesante de acumulación del capital del sistema imperial hegemónico y global expropia la justicia de los pueblos. El contraderecho expropia al Derecho su justicia, y a esta, todo contenido material. En su lugar, "se abre la puerta a la injusticia, llenando los ordenamientos normativos con cualquier contenido al servicio del imperio [al servicio de la lógica de la acumulación] y dotándolos con el poder de la violencia" (Salamanca 2011a, 133), pues aquellos pueblos que busquen la liberación del sistema para su autodeterminación son atacados con el contraderecho de matarlos o intervenir "humanitariamente" en nombre de los "derechos humanos". La justicia solo se ajusta a la aplicación concreta del contraderecho. Así, este sistema jurídico materializa no la justicia sino la maldad. Finalmente, el sistema imperial hegemónico y global expropia la aplicación del Derecho. Solo unos cuantos sacerdotes que tengan la llave para desencriptar las claves del sistema-jurídico pueden interpretar y aplicar el derecho, de acuerdo con el sistema de contraderechos.

\section{La respuesta del sistema capitalista}

Como ya mencionamos, la estructuración del capitalismo está en función a la lógica de la acumulación. El despojo es algo inevitable dentro del sistema capitalista. Sin embargo, algunos podrán objetar, con justa razón, que en décadas anteriores, después de la Segunda Guerra Mundial, la desigualdad no era tan distante como ahora, con políticas económicas que se fundamentaban en un desarrollo ampliado del Estado social y sus políticas. El Estado jugaba un papel preponderante en la regulación del mercado, con el objetivo de evitar posibles aumentos en la concentración de los ingresos en pocas manos. Para algunos, durante esta época el capitalismo adquirió un rostro humano, una añoranza que hoy se quiere repetir para rescatar al sistema. ¡Pero no nos dejemos engañar con miel envenenada!, como lo hicieron los socialdemócratas: el capitalismo jamás tendrá un rostro 
humano. Franz Hinkelammert $(2018,156)$ nos abre los ojos y devela que el rostro humano del capital solo se trató de un arma para ganar la Guerra Fría, dado que en el otro bloque se tenían países socialistas de corte productivista, que buscaban llevar a su población a una situación de satisfacción de necesidades en un grado alto y suficiente para todos. El bloque capitalista, principalmente los Estados Unidos, los consideró un enemigo peligroso sobre todo por razones ideológicas. El Estado de bienestar es utilizado para la contención del cambio social y la perpetuación de la servidumbre voluntaria de los pueblos (Marcuse 1993, 82).

Por lo anterior, no es extraño que a los EUA y sus aliados europeos, cuando sintieron que habían ganado la Guerra Fría, el rostro humano del capitalismo les sobraba, impulsándose toda una serie de medidas liberalizadoras del mercado. La ideología neoliberal, difundida por los grupos económicos de poder, amparados por Thatcher y Reagan, declaraban enemigo de la libertad toda intervención al mercado. Ahora al mercado se le declara como una "institución perfecta", en la cual no se debe de intervenir o adaptar bajo ninguna condición. La ley del mercado es la ley absoluta, y toda acción humana si es posible, tiene que ser privatizada, para que esté también penetrada por el laissez faire. Esto da lugar para Hinkelammert (2018) a un totalitarismo del mercado. Ya no hay otro proyecto histórico, aunque de misma matriz moderna-colonial como lo fue el socialismo, que contradiga al sistema capitalista. La postmodernidad ha cumplido su fin - como veremos más adelante- deslegitimando todo proyecto histórico que busque una alternativa, pues solo existe el capitalismo. ¡Vivimos en un totalitarismo! Solo que ahora del mercado.

La respuesta del sistema a la contradicción ecológica y la desigualdad social apunta al desarrollo de un capitalismo sostenible o sustentable en función del desarrollo social. En el informe Brundtland de 1987 de la ONU (Ilamado también "nuestro futuro común") se proyectó el ideal de desarrollo sostenido, entendiéndolo como "la capacidad de satisfacer las necesidades del presente sin comprometer la habilidad de las futuras generaciones de satisfacer sus propias necesidades". No obstante, el Programa de Naciones Unidas para el Medio Ambiente (PNUMA) y otros actores económicos internacionales relacionaron el desarrollo sustentable con el crecimiento económico. Años más tarde, en 1997, en el informe "Cambio Global y Desarrollo Sustentable", la noción de sustentabilidad relacionada con el crecimiento económico estaba ya bien enraizada en el PNUMA, al afirmar que "la protección ambiental y el crecimiento económico a largo plazo no son incompatibles, sino complementarios... y 
mutuamente dependientes". Esta visión de sustentabilidad se ha refrendado cumbre tras cumbre, desde los "Objetivos del Desarrollo del Milenio" hasta los "Objetivos del Desarrollo Sustentable" del 2015.

La noción de sustentabilidad proyectada en estos informes y acuerdos que se han derivado, nunca abandona la matriz económica productivista con fines acumulativos, aun en su versión de economía verde impulsada en Rio+20 en $2010^{10}$. Se parte del hecho que pobreza y degradación ecológica se condicionan y producen mutuamente, en lo cual coinciden diversos analistas y movimientos de las periferias. Sin embargo, no se analizan las causas reales que originan la pobreza y el deterioro ambiental, produciendo un gran equívoco al afirmar que cuanto más desarrollo menos miseria y mejor protección ambiental.

En contradicción con el capitalismo sustentable o "verde", y los denominados "estados plurinacionales", especialmente desde las periferias surgen movimientos sociales de carácter antisistémico, que tienen como objetivo la construcción de otro mundo y no agotan sus fuerzas en una reforma del sistema, entrando así en la búsqueda de otro paradigma capaz de transformar la lógica de la muerte del capital. En ese sentido pasan del simple antihegemonismo (propio de la dimensión de lucha del paradigma postmoderno multicultural) a una postura antisistémica. La dimensión ecológica está cada vez más presente en la acción y reflexión de estos movimientos, que no se limitan solo a organizaciones ecologistas, sino también va siendo una consideración más tenida en cuenta por los movimientos campesinos, feministas, indígenas, religiosos, como se demostró en la amplia red heterogénea del Foro Mundial de Porto Alegre, celebrado en 2001, y foros posteriores. Löwy (2012) destaca, como un sorprendente ejemplo de esta integración orgánica de las cuestiones ecológicas, al Movimiento de los Trabajadores Rurales sin Tierra (MST) brasileño, por su lucha de una reforma agraria radical y por otro modelo de agricultura, pues sus cooperativas agrícolas practican una agricultura biológica cuidadosa con la biodiversidad y el medio ambiente en general. La experiencia brasileña no es la única. En otros muchos países se conocen este tipo de movimientos que encuentran un amplio apoyo de la población.

Esta crisis también se evidencia en la dificultad que experimenta el Norte hegemónico para hallar soluciones oportunas e imaginar nuevas alternativas históricas al paradigma civilizatorio actual, no

10 Para una breve explicación sobre la economía verde consúltese: https://www. ecointeligencia.com/2016/01/economia-verde/ 
así en las periferias. Desde la década de los 60, con las atrocidades de las guerras en los distintos frentes y el ánimo revolucionario que aún se encontraba vivo en la época, empiezan a surgir al margen de la totalidad moderna (África, Asia y América Latina), movimientos críticos que partían de su propia realidad regional, protagonizados por aquellos Otros que la modernidad encubrió históricamente ${ }^{11}$. También desde las metrópolis imperiales, lo subalterno interpela exigiendo voz y derechos, gestándose movimientos raciales (afrodescendientes), feministas, obreros, homosexuales, estudiantiles. Lo disidente, lo diferente, empieza a tomar protagonismo en la historia mundial, proclamándose el agotamiento de la modernidad. Así, durante esta década y sobre todo en los 70 , surge lentamente una cierta crítica al modelo civilizatorio moderno en su universalismo, fundacionalista o dogmático.

En América Latina, se sucedieron secuencialmente entre la década de los 60 y 70 toda una serie de acontecimientos históricos que exigían un cambio en las estructuras y una reorganización en el poder, desde el populismo como vía alterna al capitalismo hasta eventos que significarían una irrupción ideológica como la Revolución Cubana, el Concilio Vaticano II expresado en la Conferencia Episcopal de Medellín, la Guerra Fría y el surgimiento de figuras políticas como Fidel Castro, Ernesto Guevara, Salvador Allende, Camilo Torres, entre otros. La situación histórica provocada por las estructuras deshumanizadoras y aberrantes ocasionó la reacción en los diversos ámbitos, como el mundo de la investigación, la política y la práctica religiosa. Esto se manifestó en la toma de conciencia de la realidad del mundo periférico que dio pie al surgimiento de un pensamiento latinoamericano de liberación, repensando al colonialismo europeo y su herencia. Se trataba de una ruptura epistemológica frente al carácter colonial de las ciencias en general, y las ciencias sociales y la filosofía en particular, y una incesante búsqueda de la concientización emancipadora de los sujetos para la transformación de la realidad institucionalizada.

Como respuesta a esta crisis se va gestando desde el Norte hegemónico el paradigma postmoderno con matiz multicultural, pues resultó funcional al sistema-mundo capitalista-moderno-colonial, ya que, paradójicamente, terminó por afirmar las estructuras de dominación del proyecto histórico capitalista-moderno-colonial como único paradigma civilizatorio (metarrelato), solo que con un rostro postmoderno y

11 Esto no significa que desde 1492, con el "mal Ilamado" descubrimiento de América, no se dieran las primeras críticas al modelo civilizatorio de la modernidad y sus lógicas genocidas y encubridoras del Otro. 
comprensivo con las minorías étnicas. La postmodernidad surge como una expresión de rechazo total del paradigma civilizatorio de la modernidad en crisis. El rechazo a sus modos de racionalidad, valores y grandes narrativas, que antes respondían íntegramente a las inquietudes y necesidades de la humanidad. Ante la creciente desconfianza en modelos unívocos filosóficos y científicos como el racionalismo liberal y el formalismo positivista, el movimiento postmoderno muestra la vertiente universalista como propia del terror y de la violencia de la racionalidad moderna. Se antepone la diferencia, la multiplicidad, la fragmentariedad y deconstrucción de todo macro relato universal. Se abre la puerta a lo equívoco como comprensión de la realidad social, repensando patrones alternativos de fundamentación.

Con la muerte de los metarrelatos se niega todo proyecto histórico que tenga por programa la idea de que el mundo puede ser transformado en favor de "los condenados de la tierra", que ofrezca una fuerza alternativa a la barbarie del sistema-mundo capitalistamoderno-colonial. Con la postmodernidad se inaugura el discurso que se resume en el conocido mensaje de "no hay alternativa", hemos llegado al fin de la historia y el horizonte de expectativas de vida del oprimido se reducen en pensarse solo desde el capital.

En lo que respecta al matiz multicultural de la postmodernidad, como mencionamos, a partir de la década de los 60, lo disidente, lo diferente, empieza a tomar protagonismo en la historia mundial a través de movimientos sociales y críticos, en respuesta a las contradicciones económicas, culturales, epistémicas y políticas generadas por el sistema-mundo capitalista-moderno-colonial. El sistema tiene que hacer frente cada vez más a grupos minoritarios que exigen reconocimiento de su identidad y respeto a su diversidad cultural, encubiertos históricamente por la modernidad. Para gestionar este conflicto étnico-cultural se dio paso al multiculturalismo. El paradigma postmoderno toma a la diversidad cultural como un aspecto multicolor e inconmensurable. Pero detrás de este supuesto reconocimiento de los derechos de las "minorías" (aunque no siempre de alcance universal), forjados por las luchas sociales, se esconde una estrategia para engullir otras visiones del mundo y perpetuar el síndrome de la ideología de la cultura superior característico de la modernidadcolonialidad. En pocas palabras, mediante el multiculturalismo, el sistema-mundo capitalista-moderno-colonial, de carácter globalizador y postmoderno, acepta y parte de la diversidad (exterioridad) étnicocultural -multiculturalismo - y busca subsumir lo "diferente" dentro de su lógica de acumulación y poder en sus estructuras establecidas, 
presentando el diálogo entre culturas como algo inconmensurable, o a lo mucho en un diálogo unidireccional que se abstrae de toda materialidad, dejando intactas las asimetrías de poder existentes.

El reconocimiento de las "minorías" y su incorporación al sistema resulta muy funcional al capitalismo, pues vuelve productivo al "indio(a)", "negro(a)", "mestizo(a)", encuentra ganancia en el homosexual (p.ej. los negocios gay friendly), y apoya las luchas de igualdad femenina para abaratar más los costos de mano de obra al incorporarla en el mercado laboral. Esta incorporación de las "minorías" explica la aparente paradoja señalada por Wallerstein (2016) de porqué en momentos de estancamiento económico los propietariosproductores impulsan procesos de proletarización, ocasionando cambios en las relaciones de producción, cuando aparentemente estas medidas tendrán una reducción de los niveles de ganancia. La respuesta es sencilla: la incorporación de nuevas zonas económicas y, por ende, de mano de obra, permite exportar los costos de producción y externalidades a las periferias, y obtener grandes ahorros porque en ellas la mano de obra es peor pagada que en el centro del sistemamundo, además de otras ventajas que los estados periféricos les dotan para incentivar la inversión (flexibilidad laboral, débil regulación ambiental, incentivos fiscales, etc.). El aprovechamiento de las minorías resulta esencial, ya que sus condiciones histórico-materiales, que se vienen configurando desde la colonización europea por el patrón de poder expropiatorio sobre el control y explotación del trabajo y la naturaleza, posibilitan que acepten una "servidumbre voluntaria" a cambio de un salario muy por debajo de la mano obrera del Norte, y además le sirve al capital para desplazar todo modelo de producción que no es capitalista, al penetrar sus intereses de mercado en los espacios socio-territoriales. Como vemos, los mecanismos de despojo se renuevan según las circunstancias.

En cuestión jurídica, frente a la contradicción provocada por un capitalismo industrial y despótico, insostenible durante la segunda mitad del siglo $x x$, se proclamó la declaración de los derechos humanos, y el reconocimiento sucesivo de otros derechos (p.ej. los culturales, económicos, etc.). Esto en respuesta a la devastación humana ocasionada por la segunda guerra mundial, y después por la diversidad de movimientos que fueron visibilizándose, en especial los movimientos de liberación, que reclamaban el reconocimiento de sus derechos. Por primera vez se pretende que el reconocimiento de los derechos humanos tenga un alcance global, configurando un sistema jurídico estructurado e internacional de derechos con el fin de "mantener la paz y la seguridad internacionales; fomentar entre las 
naciones relaciones de amistad basadas en el respeto al principio de la igualdad de derechos y al de la libre determinación de los pueblos; y realizar la cooperación internacional en la solución de problemas internacionales de carácter económico, social, cultural o humanitario, y en el desarrollo y estímulo del respeto a los derechos humanos y a las libertades fundamentales de todos, sin hacer distinción por motivos de raza, sexo, idioma o religión"12. A raíz de los problemas ecológicos que comienzan a cobrar relevancia en la década de los 60, el sistema internacional de derechos humanos (el sistema imperial), comienza a señalar líneas de acción para la promoción y protección medio ambiental, la Declaración de Estocolmo sobre el Medio Humano y sus Principios formaron el primer cuerpo de una "legislación blanda" para cuestiones internacionales relativas al medio ambiente.

El marco jurídico internacional medio ambiental se ciñe en función al sistema internacional de los derechos humanos. Su catálogo se integra conforme a la diversidad de determinados problemas ambientales. Por ello existen grupos normativos diferenciados y especializados en espacios como el mar, la biosfera o el espacio ultraterrestre; otros protegen la biodiversidad, la capa de ozono o el patrimonio natural y cultural, la conservación de los suelos: especial referencia a la lucha contra la desertificación, o el control internacional de los desechos. También, otros abordan los problemas ambientales derivados de los conflictos armados, el uso de armas nucleares, químicas o biológicas, o el comercio de las especies; recientemente se ha creado un grupo normativo que abarca el cambio climático, vinculando las respuestas posibles a la crisis ecológica según modelos de desarrollo "sostenible" o "sustentable", con miras a transitar hacia un capitalismo o economía verde.

Tales grupos normativos establecen una serie de principios, denominados principios del derecho internacional ambiental, como el principio de cooperación internacional, el principio de prevención del daño ambiental transfronterizo, el principio de responsabilidad y reparación de daños ambientales, los principios de evaluación de impacto ambiental, de precaución y "quien contamina paga", el principio de participación del público, etc. Además, establecen procedimientos para la aplicación del derecho internacional ambiental, análogos a la aplicación del derecho internacional público. De ese escenario internacional se derivan marcos de protección nacionales que confían la contención de sus problemas ambientales, con la finalidad

12 Objetivos trazados en la Carta de las Naciones Unidas. 
de gestionar eficaz y eficientemente los impactos ambientales, y sus residuos.

Como vemos, el sistema imperial de los derechos humanos (contraderechos), expropia a los pueblos del mundo su capacidad de producción jurídica, y les implanta un marco jurídico internacional que desplaza y oculta una relación Otra de los pueblos con la naturaleza, imponiendo una visión androcéntrica dentro de los esquemas del sistema capitalista e ideológicos de la modernidad-colonialidad. Este sistema escruta permanentemente las constituciones, leyes y tratados de los pueblos con la finalidad de destrozarlos y conseguir extender el dominio ideológico, económico y militar. En ese sentido, no es extraño que los sistemas nacionales de protección ambiental estén diseñados con el objetivo, no de evitar la contaminación y depredación de las fuentes naturales de vida, la cual afecta al equilibrio del sistemaTierra, sino de contaminar de a poco, es decir, se trata de extender tecnológicamente el modelo desarrollista y extractivista en el tiempo, no de formular una alternativa al paradigma progresista o desarrollista que impone la lógica de acumulación capitalista.

El derecho internacional ambiental se reviste con un fundamento androcéntrico, ya que está orientado primordialmente a garantizar el bienestar humano, tomando la protección de la naturaleza para conseguir ese fin. Así los derechos a un ambiente sano están comprendidos dentro de los derechos humanos, reproduciendo la lógica de dominación de la naturaleza por el hombre. Esto significa que se protege al medio ambiente en la medida en que los daños a él causados puedan afectar a los seres humanos y sus derechos ${ }^{13}$. En estos casos cuando hay daños ambientales y afectan de manera directa o indirecta a los seres humanos, estos pueden ser indemnizados, reparados y/o compensados, bajo criterios económicos, reduciendo a la naturaleza en mercancía que puede ser valorada para los fines humanos. De ahí que Gudynas (2016) señale que en el derecho internacional ambiental se aplique la justicia ambiental, debido a que trata de precautelar (con base en el principio precautorio) los derechos humanos frente a los daños ambientales que los afecten, estableciendo mecanismos de sanción, compensación y reparación entre seres

13 No es extraño que en el artículo segundo de la Declaración de Estocolmo sobre el Medio Humano y sus Principios, se formule: "la protección y mejoramiento del medio humano es una cuestión fundamental que afecta al bienestar de los pueblos y al desarrollo económico del mundo entero, un deseo urgente de los pueblos de todo el mundo y un deber de todos los gobiernos" (Declaración de Estocolmo sobre el Medio Humano y sus Principios, 1972) 
humanos, mismos que deben ser adoptados por los sistemas nacionales de protección. ¡Otro ejemplo más de como el sistema imperialista de los derechos humanos expropia la aplicación de la justicia a los pueblos!

Durante el último tercio del siglo xx, el derecho ambiental adquirió relevancia, vinculándolo con el concepto de desarrollo "sostenible" o "sustentable". Como señalamos en el capítulo primero, la noción de "sustentabilidad" o "sostenibilidad" nunca abandona la matriz económica productivista con fines acumulatorios, aun en su versión de economía verde impulsada en Rio+20. Se plantea compaginar el crecimiento económico con el equilibrio de la biósfera. El derecho internacional ambiental, si bien puede proporcionar mecanismos de defensa jurídica que son aprovechados por los pueblos afectados por un daño ambiental generado por la lógica capitalista, acota a la praxis jurídica en términos del sistema capitalista, dejando a la naturaleza a merced de ser torturada en su totalidad por el capitalismo con rostro verde.

\section{4. ¿La necesidad de transitar a un nuevo paradigma?}

La crisis actual está poniendo en peligro no solo la supervivencia del género humano y la Tierra, también del mismo sistema. Las fuentes de acumulación del capital empiezan a agotarse. El capitalismo se limita a sí mismo al afectar sus propias condiciones sociales y ambientales (fractura metabólica). Para Wallerstein (2016), el capitalismo histórico entró en su crisis estructural a comienzos del siglo XX, encontrando un desarrollo de ganancia artificial, ya no en la economía real (una caída del sector productivo), sino en la del sector financiero mediante la especulación (economía virtual). Además, con la explotación de los recursos naturales que se intensificó, especialmente después de la Segunda Guerra Mundial y en particular con el Consenso de Washington, se ha disparado el nivel per cápita del consumo de energía, y por ende, el aumento de los residuos. En pocas palabras, esta fase del capitalismo se caracteriza por una explotación acelerada de la naturaleza y el incremento alarmante de la desigualdad entre la población mundial. El capitalismo nos está despojando de las últimas migajas de pan arrebatadas al burgués por las luchas sociales, generando la respuesta de nuevas demandas en los movimientos sociales y antisistémicos (p.ej. ecológicas). En ese sentido, no es extraña la advertencia del execonomista en jefe del Fondo Monetario Internacional, Raghuram Rajan (BBC 2019), cuando señala que el 
capitalismo está bajo una seria amenaza porque "ha dejado de proveer para las masas. Y, cuando eso sucede, las masas se rebelan contra el capitalismo".

Es oportuno preguntarse: ¿se puede encontrar una verdadera solución radical al problema de la crisis ecológica y humana, desde la lógica capitalista, generadora de escandalosas desigualdades y estragos catastróficos? Y, por lo tanto: ¿se pueden materializar los derechos de los pobres y de la naturaleza desde el sistema-mundo jurídico y su ideología, el cual se configura en función a la lógica de la acumulación del capital y la modernidad-colonialidad? Está claro que se configura en la pregunta una contradicción in adiecto. No es posible esperar la solución al problema medio ambiental y de la desigualdad social desde la lógica de acumulación capitalista que los causó. El discurso se renueva, pero su lógica sigue siendo la misma, al tiempo que los problemas ambientales y la desigualdad social se agudizan conforme voy escribiendo estas líneas. En consecuencia, coincidimos con Houtart (2015), cuando afirma que la lógica del capitalismo ha creado una crisis de civilización, lo que nos obliga a revisar el paradigma mismo (la orientación de base) del vivir colectivo de la humanidad del planeta, tal como fue definido por el capitalismo, y agregaría, la modernidadcolonialidad, que hoy se ha globalizado.

Dadas las múltiples dimensiones de la crisis causada por el paradigma actual y su configuración de los fundamentos de la vida colectiva impuesta a los pueblos del mundo, se vuelve imperativo la dimensión ecológica en todas las luchas por los derechos humanos. Es hora de empezar a hablar de los derechos de la naturaleza. ¿De qué sirve solo luchar para que el pobre tenga pan en su mesa, si la tierra donde cosecharon el trigo para ese pan se volverá infértil? ¿De qué sirve darle agua al sediento, si después de dársela la seguiremos contaminando, olvidando que donde hay agua hay vida? ¿De qué sirve vestir al desnudo, si al vestirlo seguiremos desnudando a la Tierra en sus bosques, selvas y maravilloso verdor, ocasionando grandes holocaustos naturales? ¿De qué sirve luchar solo para la liberación del oprimido, si por liberarlo terminaremos oprimiendo a la Tierra, destruyendo nuestra casa común, cometiendo un genocidio a la creación? ¡El derecho a la revolución de los pueblos es también el de la revolución de la Tierra! 


\section{Referencias bibliográficas}

BBC Mundo. 2019. " «El capitalismo está bajo seria amenaza»: las advertencias de Raghuram Rajan, el economista que predijo la crisis financiera global". BBC Mundo, 17 de marzo. Acceso el 2 de abril del 2019. https://acento. com.do/2019/economia/8661964-capitalismo-esta-seria-amenaza-lasadvertencias-raghuram-rajan-economista-predijo-la-crisis-financiera-global/

Boff, Leonardo. 2011. Ecología: el grito de la tierra, el grito de los pobres, Madrid: Trotta.

Dussel, Enrique. 2004. "Sistema-mundo y transmodernidad", en Modernidades coloniales, editado por Saurabh Dube, Ishita Banerjee y Walter Mignolo, 201-226, México, D.F.: Colegio de México.

Gudynas, Eduardo. 2016. Derechos de la naturaleza. Ética biocéntrica y politicas ambientales, Quito: Abya-Yala.

Harvey, David. 2005. El nuevo imperialismo: acumulación por desposesión, Buenos Aires: CLACSO.

Hinkelammert, Franz. 2018. Totalitarismo del mercado, México, D.F.: Akal.

Houtart, François et al. 2017. Las relaciones Sur-Sur, y el desafío de un nuevo proyecto de civilización, Quito: IAEN.

Houtart, François. 2015. El bien común de la humanidad, México, D.F.: CENEJUS-UASLP.

Löwy, Michael. 2012. Ecosocialismo. La alternativa radical a la catástrofe ecológica capitalista, Madrid: Biblioteca Nueva.

Lugones, María. 2008. "Colonialidad y género", Tabula Rasa, 9: 73-101.

Marcuse, Herbert. 1993. El hombre unidimensional. Ensayo sobre la ideología de la sociedad industrial avanzada, Buenos Aires: Planeta-Agostini.

Marx, Karl. 2016. Manifiesto comunista/Sobre la cuestión judía, México, D.F.: Editorial Lectorum.

Marx, Karl. 2006. El capital. Tomo I. El proceso de acumulación capitalista, Archivo Chile. Acceso el 7 de enero del 2019. http://www.archivochile. com/Marxismo/Marx\%20y\%20Engels/kmarx0010.pdf

O'Connor, James. 2000. "¿Es posible el capitalismo sostenible?", Papeles de Población 24: 9-35.

O'Connor, James. 2001. Causas naturales. Ensayos de marxismo ecológico, México. D.F.: Siglo XXI.

Polanyi, Karl. 2006. La gran transformación, México. D.F.: FCE.

Prado, Abdennur. 2018. Genealogía del monoteísmo. La religión como dispositivo colonial, México D.F.: Akal.

Puleo, Alicia H. 2011. Ecofeminismo para otro mundo posible, Madrid: Ediciones Cátedra.

Quijano, Aníbal. 2014. "Colonialidad del poder, eurocentrismo y América Latina", en Cuestiones y horizontes. De la dependencia históricoestructural a la colonialidad/descolonialidad del poder, Aníbal Quijano, 777-832, Buenos Aires: CLACSO. 
Rosillo, Alejandro. 2011. Los inicios de la tradición iberoamericana de derechos humanos, San Luis Potosí-Aguascalientes: UASLP-CENEJUS.

Salamanca, Antonio. 2010. "Iusmaterialismo. Teoría del derecho de los pueblos", Revista Critica Jurídica, 29: 83-127.

Salamanca, Antonio. 2011a. Teoría Socialista del Derecho (Iusmaterialismo). Tomo I, Quito: Editorial Jurídica del Ecuador.

Salamanca, Antonio. 2011b. Teoría Socialista del Derecho (Iusmaterialismo). Tomo II, Quito: Editorial Jurídica del Ecuador.

Salamanca, Antonio. 2016. El fetiche jurídico del capital: hegemonía global mediante los estudios de derecho, Quito: IAEN.

Segato, Rita L. 2018. "Manifiesto en cuatro temas", Critical Times, 1: 212225.

Stefanoni, Pablo. 2010a. "¿A dónde nos lleva la pachasmismo?". Rebelión, 28 de abril. Acceso el 2 de marzo de 2019. http://www.rebelion.org/noticia. php?id $=104803$

Stefanoni, Pablo. 2010b. "Indianismo y pachasofismo". Rebelión, 4 de mayo. Acceso el 2 de marzo del 2019. http://www.rebelion.org/mostrar. php?tipo $=5 \&$ id $=$ Pablo $\% 20$ Stefanoni\&inicio $=150$

Torre, Jesús A. de la. 2004. Tradición Iberoamericana de derechos humanos, México, D.F.: Porrúa.

Wallerstein, Immanuel. 2016. El capitalismo histórico, México: Siglo XXI.

Wallerstein, Immanuel. 2017. Análisis de sistema-mundo. Una introducción, México, D.F.: Siglo XXI. 


\section{Copyright}

Deusto Journal of Human Rights / Revista Deusto de Derechos Humanos is an Open Access journal; which means that it is free for full and immediate access, reading, search, download, distribution, and reuse in any medium only for non-commercial purposes and in accordance with any applicable copyright legislation, without prior permission from the copyright holder (University of Deusto) or the author; provided the original work and publication source are properly cited (Issue number, year, pages and DOI if applicable) and any changes to the original are clearly indicated. Any other use of its content in any medium or format, now known or developed in the future, requires prior written permission of the copyright holder.

\section{Derechos de autoría}

Deusto Journal of Human Rights / Revista Deusto de Derechos Humanos es una revista de Acceso Abierto; lo que significa que es de libre acceso en su integridad inmediatamente después de la publicación de cada número. Se permite su lectura, la búsqueda, descarga, distribución y reutilización en cualquier tipo de soporte sólo para fines no comerciales y según lo previsto por la ley; sin la previa autorización de la Editorial (Universidad de Deusto) o la persona autora, siempre que la obra original sea debidamente citada (número, año, páginas y DOI si procede) y cualquier cambio en el original esté claramente indicado. Cualquier otro uso de su contenido en cualquier medio o formato, ahora conocido o desarrollado en el futuro, requiere el permiso previo por escrito de la persona titular de los derechos de autoría. 